\title{
Coproductie: \\ 'loss' of oplossing?
}

Rianne van Melik

\begin{abstract}
Vanwege toenemende bezuinigingen zijn gemeenten steeds minder in staat zorg te dragen voor de aanleg en het beheer van de openbare ruimte. Meer samenwerking tussen publieke en private partijen kan een oplossing zijn, maar lijkt een taboe door angst voor privatisering. Toch is coproductie - ook in Nederland allesbehalve nieuw en kan het mogelijkheden bieden voor de handhaving en verbetering van openbare ruimte.
\end{abstract}

De aanleg, maar vooral het beheer, van openbare ruimte is een kostbare aangelegenheid. PricewaterhouseCoopers berekende in 2010 dat meer dan tweederde van de Nederlandse gemeenten te maken heeft met tekorten op hun totale begroting. Voor veel overheden zit er niets anders op dan te bezuinigen, ook op investeringen in de openbare ruimte. Tegelijkertijd bestaat er een wens bij andere partijen een rol te spelen in de openbare ruimte. Dit varieert van burgers die moestuintjes willen aanleggen in gemeentelijke plantsoenen tot woningcorporaties en andere investeerders die de waarde van hun vastgoed willen verhogen door de omgeving te verbeteren.

Toenemende samenwerking tussen publiek en privaat - ook wel coproductie genoemd - ligt dan ook voor de hand, maar de angst voor privatisering, toenemende regulering en vercommercialisering lijkt vooralsnog te overheersen. Het dominante beeld in wetenschap en beleid is dat openbare ruimten voor iedereen vrij toegankelijk moeten zijn, zonder entreegelden, strenge regels of sluitingstijden. Om dat beeld waar te maken moet de openbare ruimte wel haast in publieke handen zijn. Dit artikel stelt de vanzelfsprekendheid van gemeentelijk beheer en eigendom van Nederlandse openbare ruimte ter discussie. Hoewel ook voorbeelden zullen worden genoemd van (winkel)straten en pleinen, zal er met name ingegaan worden op groene open(bare) ruimte. Parken zijn van groot belang voor de gezondheid van stadsbewoners, sociale cohesie en toerisme. Deze voordelen zijn echter vaak impliciet, terwijl de kosten expliciet - en meestal nog voor rekening van de gemeente - zijn. Juist in de groene openbare ruimte lijkt private betrokkenheid bij aanleg en beheer een oplossing te kunnen zijn. Of is de angst gegrond en is er toch sprake van 'loss'?

\section{Historische terugblik}

Een blik in de geschiedenis laat zien dat publiek-private samenwerking op het gebied van openbare ruimte in het verleden geen taboe, maar de normaalste zaak van de wereld was. In de middeleeuwen speelden lokale overheden een dominante rol bij de ontwikkeling en uitbreiding van hun stad. Zo kocht het stadsbestuur van Hoorn in 1559 een huis naast de Waag, waardoor de Kaasmarkt als openbaar handelsplein ontstond. Ook in andere steden bemoeide de overheid zich met onder andere het soort plaveisel, de breedte van straten, de aanleg van bruggen en de handhaving van het openbare karakter van straten en parken. Toch was het stadsbestuur zeker niet de enige verantwoordelijke partij: de overheid regelde de zogenaamde openbare werken, maar de gilden voerden ze uit. Van der Cammen en De Klerk stellen dan ook dat het vertrouwde beginsel van publieke regeling en particuliere uitvoering van openbare werken berust op een lange traditie.

\section{Private betrokkenheid bij openbare ruimte was in het verleden geen taboe, maar de normaalste zaak van de wereld}

Deze private betrokkenheid duurde in wisselende mate eeuwenlang voort. Tot de negentiende eeuw waren veel open gebieden in Westerse steden privaat eigendom en beperkt toegankelijk. Bekend zijn de 


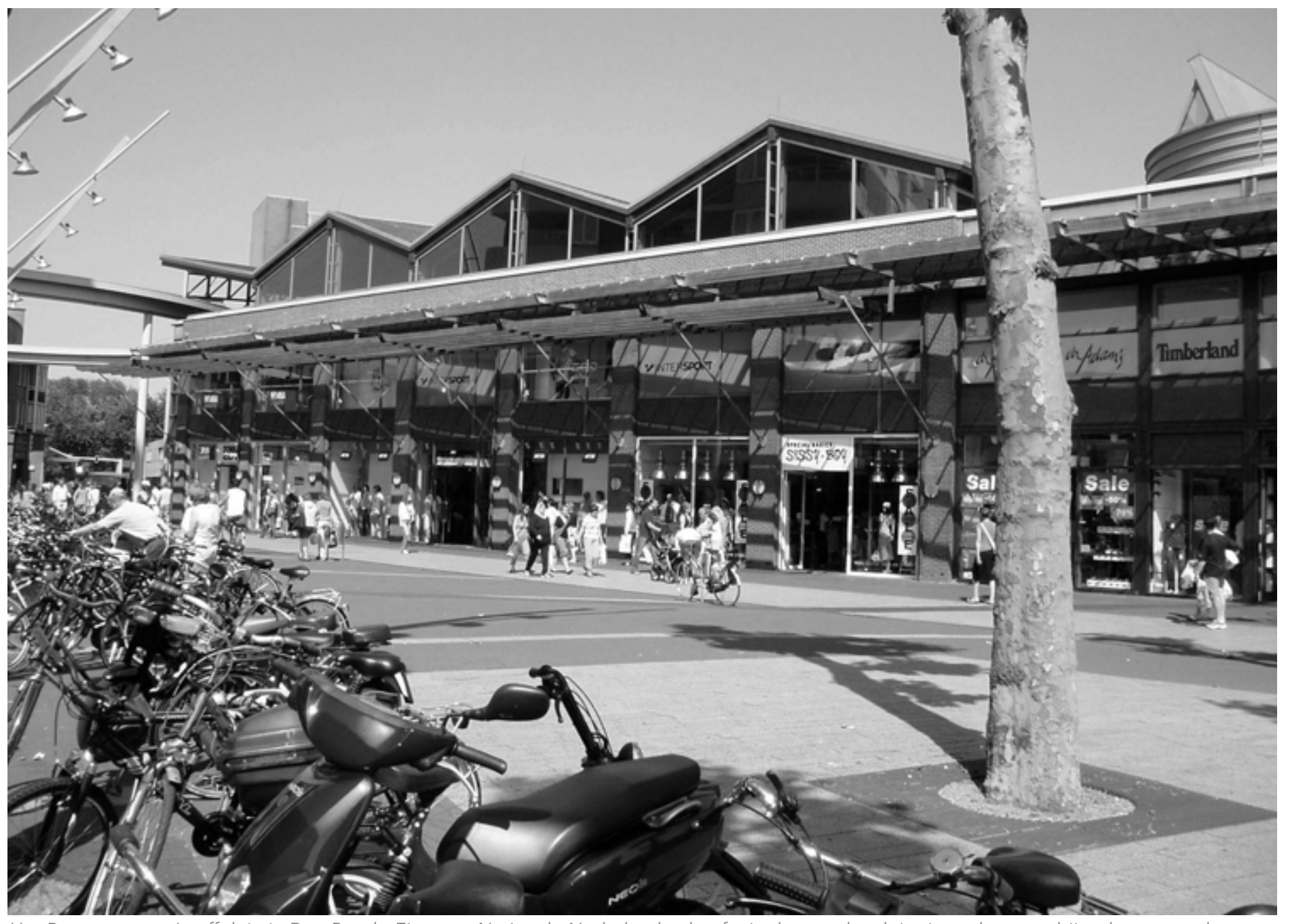

Het Burgemeester Loeffplein in Den Bosch. Eigenaar Nationale Nederlanden heeft via de grondexploitatie onder meer bijgedragen aan het herontwikkelingsbudget van het plein.

zorgvuldig beheerde, koninklijke domeinen rond Parijs, waaronder Versailles. Deze plekken dienden vaak voor vermaak van de bourgeoisie, bijvoorbeeld voor de jacht. Ook in Nederland speelde de rijke elite een belangrijke rol bij de aanleg van grote delen van de stad, zoals bij het Vondelpark (Amsterdam) en Agnetapark (Delft), dat door fabriekseigenaar Van Marken in 1884 werd aangelegd. Overtuigd van het belang van een goede woon- en werkomgeving voor het aantrekken, behouden en functioneren van zijn arbeiders, liet hij huizen, scholen en andere faciliteiten bouwen in een parkachtige omgeving. Hoewel het Agnetapark niet op alle vlakken een succes bleek (te hoge woonkosten en teveel sociale controle door Van Marken die zelf ook in het park woonde), vervulde het wel een voorbeeldfunctie in het land. Rond 1900 waren er al enige tientallen kleine particuliere tuindorpen verrezen. De negentiende eeuw kan dan ook worden betiteld als een periode waarin de private sector een dominante rol speelde bij de creatie van open(bare) ruimten.

In de tweede helft van de negentiende eeuw werden parken en andere open gebieden steeds vaker opengesteld voor het publiek. Industrialisatie en urbanisatie hadden voor een explosie van steden gezorgd. De leefcondities van de arbeidersklasse waren vaak erbarmelijk en leidden tot de uitbraak van ziektes zoals cholera en tuberculose. De bevolking groeide exponentieel, zodat er al snel in veel Neder- landse steden sprake was van een nijpende overbevolking binnen de stadsmuren. De openbare ruimte kwam steeds meer onder druk te staan, terwijl de vraag naar groen en ruimte juist steeg. De afbraak van stadsmuren zorgde in veel steden voor uitbreidingsmogelijkheden. In Utrecht raakten de stadsmuren in onbruik door de ontdekking van granaten en aanleg van de Nieuwe Hollandse Waterlinie (1816-1821). Op de voormalige omwalling werd in 1872 het Singelpark aangelegd naar een ontwerp van landschapsarchitect Zocher. Het gebied rondom de Singel werd zo getransformeerd van verdedigingslinie naar openbaar recreatiegebied.

Ook buiten Nederland zorgden industrialisatie en de groei van steden voor een groeiende waardering voor groen. Soms dienden nieuwe groenvoorzieningen nog vooral voor het private woongenot van welgestelden - zoals de Georgian Squares in Londen en Dublin - maar er werden door overheden ook grote publieke parken voor stedelingen aangelegd, zoals Central Park in New York. Veel van de nieuwe recreatiegebieden werden dan ook publiek domein: in eigendom en beheer van de lokale overheid en toegankelijk voor iedereen. Dit luidde een nieuw tijdperk in, waarin de rol van de overheid in de (Nederlandse) stedenbouw groter werd.

Na de Tweede Wereldoorlog werd de Nederlandse overheid steeds dominanter als programmeur, planner en financier van stedelijke 
ontwikkelingprocessen. In de jaren vijftig en zestig richtte ze zich voora op wederopbouw en stadsvernieuwing, met name in gebombardeerde steden. De focus lag op de gebouwde omgeving om de woningnood tegen te gaan. Vanaf de jaren zeventig verschoof dit geleidelijk naar de niet-bebouwde, open(bare) ruimte. Straten in Nederlandse binnensteden werden tot voetgangersgebied verklaard en vanaf de jaren tachtig werden vele havengebieden gerevitaliseerd. In navolging van de 'Vierde Nota Ruimtelijke Ordening' (1988) en succesvoorbeelden als de 'Kern Gezond Nota' in Den Haag werden steeds meer stadspleinen en (winkel)straten herontwikkeld. Zowel op nationaal als lokaal niveau werd de openbare ruimte een overheidsaangelegenheid.

\section{Toename van private betrokkenheid}

Deze dominante rol van de overheid bij de handhaving en verbetering van openbare ruimte lijkt langzamerhand te veranderen. Steeds vaker worden burgers en bedrijven erbij betrokken en is de gemeente niet (meer) de enige verantwoordelijke. De mate van coproductie verschilt. Soms is de samenwerking zeer vergaand, zoals bij de Beurstraverse.

Deze 'Koopgoot' is in 1996 aangelegd door een consortium dat - naast de gemeente Rotterdam - bestaat uit de ING en pensioenfonds Focas. De partijen betalen samen voor het onderhoud en de beveiliging van de verdiepte winkelstraat. Het is privaat gebied, maar wel publiek toegankelijk. Een ander voorbeeld uit Rotterdam is proefpark 'De Punt'. Dit terrein in Delfshaven van ongeveer 40 bij 400 meter lag lange tijd braak, totdat de gemeente de onafhankelijke organisatie 'Creatief Beheer' in 2004 de opdracht gaf er "iets leuks en zinvols" voor de buurt mee te doen. Het beheer - inclusief onderhoud van speeltoestellen, toezicht op de volkstuintjes en de organisatie van educatieve trajecten voor buurtkinderen - is dus als het ware door de gemeente uitbesteed aan een particuliere partij.

In andere Nederlandse steden zijn vergelijkbare voorbeelden van coproductie, hoewel zelden met zo'n grote private betrokkenheid als bij de Beurstraverse. Soms nemen private actoren het initiatief tot herinrichting, zoals VendexKBB en Multi bij het Statenplein in Dordrecht. In andere gevallen brainstormen ze actief mee over het ontwerp en/of financieren ze indirect mee aan de herontwikkeling van openbare ruimte via de grondexploitatie, bijvoorbeeld Interpolis bij het Van Heekplein in Enschede en Nationale Nederlanden bij het Burgemeester Loeffplein in Den Bosch.

Deze terugkeer naar meer private betrokkenheid heeft verschillende oorzaken. Ontwikkelaars en investeerders zijn niet (meer) alleen geïnteresseerd in hun eigendom, maar ook in de ruimte eromheen. Ze denken de waarde van hun eigendom te verhogen door de herinrichting van de omliggende openbare ruimte. Gemeenten hebben op hun

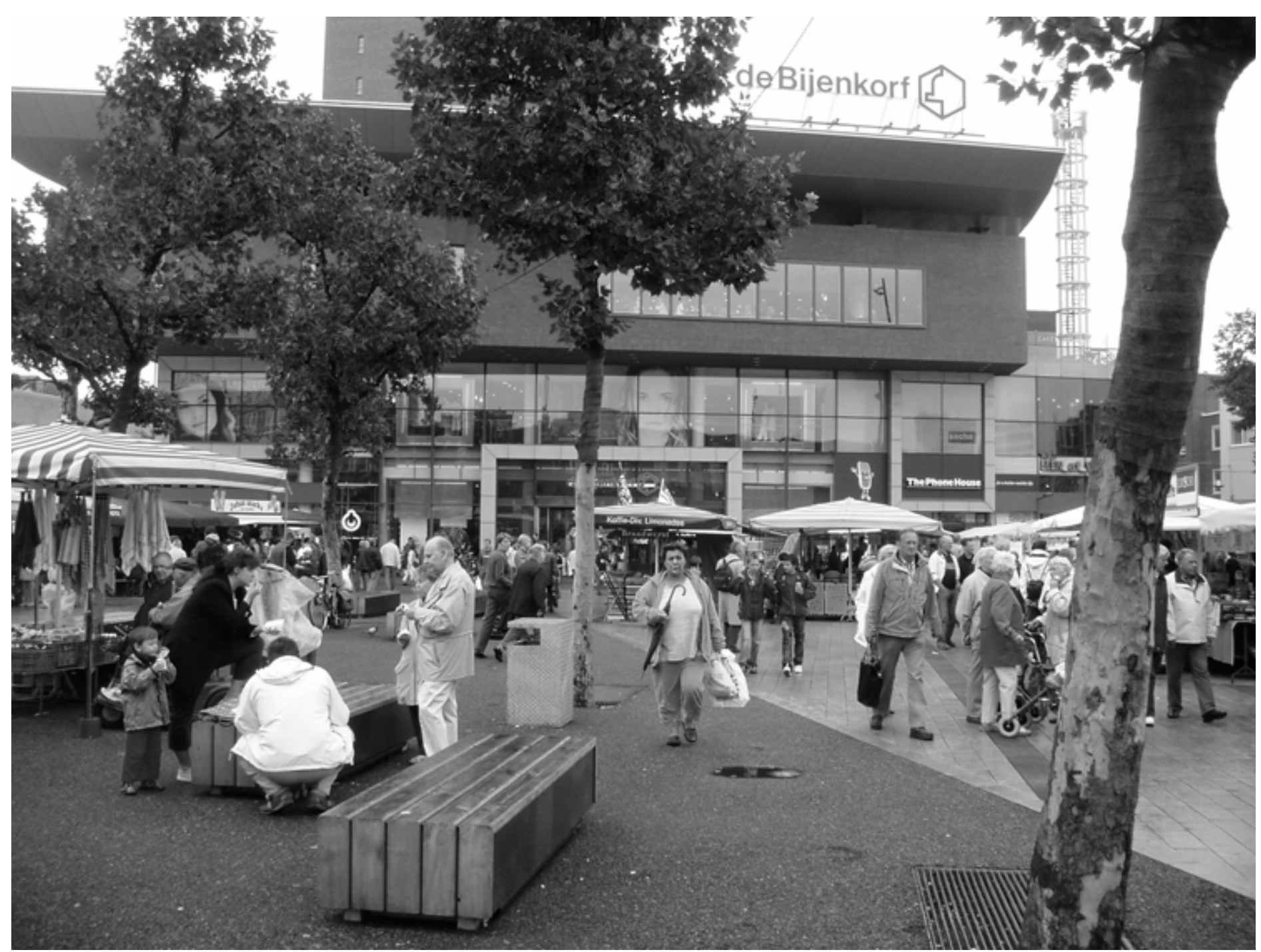

Het Van Heekplein in Enschede. Eigenaar Interpolis heeft via de grondexploitatie bijgedragen aan het herontwikkelingsbudget van het plein. 
beurt belangstelling om private partijen bij herontwikkelingsprocessen in de binnenstad te betrekken. Vanwege decentralisatie van de nationale overheid moeten ze steeds meer zelf voor hun eigen ruimtelijke ontwikkeling en inkomsten zorgen, wat nog eens wordt bemoeilijkt door de huidige economische crisis. Dit betekent dat gemeenten moeten zoeken naar andere (private) bronnen voor het financieren van ruimtelijke ontwikkelingen en tevens de stad actief moeten promoten. Dit kan gedaan worden door middel van citymarketing, maar ook door de openbare ruimte opnieuw in te richten op een spraakmakende manier. Door de handen ineen te slaan kan een win-winsituatie ontstaan voor zowel publieke als private partijen. Bovendien was de herinrichting van openbare ruimte in de jaren negentig en begin eenentwintigste eeuw vaak onderdeel van een grotere, integrale vernieuwingsslag van binnensteden. Dit betekende bijna automatisch dat niet alleen de overheid betrokken was, maar ook vastgoedeigenaren, winkeliers en inwoners. Intensievere samenwerking was dus niet alleen wenselijk, maar ook onvermijdelijk.

\section{Met een kritische blik op de haalbaarheid en gevolgen kan coproductie als oplossing worden beschouwd in plaats van verlies}

\section{'Loss of public space?'}

Toch blijft de private betrokkenheid in Nederland relatief bescheiden in vergelijking met landen als de Verenigde Staten of het Verenigd Koninkrijk. Stolk laat verderop in dit themanummer zien dat er vele voorbeelden zijn van groene openbare ruimten in New York die door private partijen zijn herontwikkeld en/of worden beheerd, zoals Bryant Park en de High Line. Het is de vraag of dergelijke initiatieven in Nederland wenselijk zijn. De wetenschap geeft hier geen duidelijk antwoord op. Enerzijds is er een groep pessimisten, waaronder Sorkin en Kohn, die private betrokkenheid zien als bedreiging voor de toegankelijkheid en diversiteit van openbare ruimten. Ze spreken in termen van 'loss' en 'end of public space' om aan te geven dat het publieke karakter van openbare ruimte verloren gaat door afsluiting, cameratoezicht, regulering en vercommercialisering. Cruciaal hierbij is dat geprivatiseerde ruimten op het eerste gezicht openbaar lijken, maar dat ze worden beheerd en gecontroleerd voor private doeleinden, en dus niet echt openbaar zijn. Door private betrokkenheid kunnen openbare ruimten niet meer functioneren als ontmoetingsplaats van een diverse groep mensen of bijvoorbeeld als protestplaats.

Anderzijds zijn er wetenschappers, zoals De Magalhães, die optimistischer zijn over private betrokkenheid. Zij stellen dat er niet simpelweg sprake is van een 'corporate take-over', waarbij het eigendom overgaat van publiek naar privaat, maar dat het in plaats daarvan gaat om een nieuwe verdeling van rollen, rechten en verantwoordelijkheden waarbij publiek en privaat met elkaar samenwerken om tot een goed eindresultaat te komen. De pessimisten schetsen volgens hen bovendien een te geïdealiseerd beeld van toegankelijkheid: geen enkele openbare ruimte is werkelijk openbaar. Er gelden altijd regels, en maatregelen die voor sommige gebruikers als beperkend worden beschouwd (zoals cameratoezicht), kunnen voor anderen juist als bevrijdend worden ervaren. Daarnaast kunnen ruimten in privaat eigendom wel degelijk het publieke belang dienen. Als het gaat over verminderde toegankelijkheid door private betrokkenheid, is het daarom de vraag voor wie een openbare ruimte minder of meer toegankelijk wordt.

\section{Privatisering vs. coproductie}

Ook buiten de wetenschap blijft privatisering een beladen term. Momenteel loopt een parlementair onderzoek naar de nadelige gevolgen van de verzelfstandiging van overheidsdiensten tussen 1990 en 2010. "Privatisering blijkt geen walhalla" kopte de Volkskrant daarover afgelopen juni. In dezelfde maand verscheen in de Britse krant 'The Guardian' een serie artikelen over de privatisering van openbare ruimte, inclusief een oproep aan de lezers om de 'verloren' publieke ruimte mee in kaart te helpen brengen. Hiermee hoopt de krant inzichtelijk te maken hoeveel openbare ruimte onder 'corporate control' is.

Deze geluiden geven privatisering alleen maar een negatieve lading. Toch is private betrokkenheid in groene openbare ruimte niet per se slecht, het kan ook juist een oplossing bieden - zoals het in het verleden ook heeft bijgedragen aan de totstandkoming van openbare ruimte. Belangrijk hierbij is het onderscheid tussen verantwoordelijkheid delen (coproductie) en het compleet overdragen aan de markt (privatisering). Coproductie gaat over het vinden van andere inkomstenbronnen of beheerders om de kwaliteit van de openbare ruimte te kunnen behouden of verbeteren, zonder dat dit meteen betekent dat het eigendom ervan overgaat in private handen. Met een kritische blik op de haalbaarheid en gevolgen ervan zou coproductie dan ook als mogelijke oplossing moeten worden beschouwd in plaats van een verlies.

Rianne van Melik (r.vanmelik@fm.ru.nl) is universitair docent binnen de sectie Geografie, Planologie en Milieu (Faculteit der Managementwetenschappen) aan de Radboud Universiteit Nijmegen.

\section{Literatuurselectie}

Cammen, H., van der \& L. de Klerk (2003) Ruimtelijke Ordening: Van Grachtengordel tot Vinex-wijk. Houten: Het Spectrum.

De Magalhães, C. (2010) Public space and the contracting-out of publicness: A framework for analysis, Journal of Urban Design 15, nr. 4, pp. 559-574

Kohn, M. (2004) Brave New Neighborhoods. The Privatization Of Public Space. New York: Routledge.

Melik, R. van (2010) Publiek versus privaat op straat: Hoe burgers en bedrijven meer kunnen worden betrokken bij publieke ruimte, Topos 20, nr.2, pp. 8-12.

Sorkin, M., ed. (1992) Variations on a Theme park: The New American City and the end of Public Space. New York: Noonday Press. 